\title{
$\mathbb{F} O \mathbb{R} \mathbb{M}$ ÇÕIS DISCURSIVAS DE UMA $\mathbb{E} \mathbb{A} \mathbb{R}$ CA GLOBAL NUMI CONTEXTO LOCAL: UMI ESTUDO INSPIRADO NO

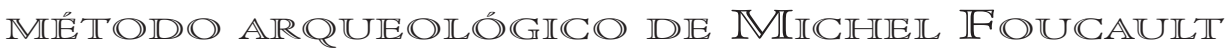

\author{
Flávia Zimmerle da Nóbrega Costa* \\ André Luiz Maranhão de Souza Leão**
}

Resirino

(

advento da globalização contribui para gerar um emaranhado campo de cruzamentos culturais e, assim, permite o estabelecimento de valores universais em meios locais. Esse contexto, aliado à cultura de massas, promoveu as marcas a símbolos culturais complexos e globais. Nosso objetivo foi buscar a compreensão de como é possível uma marca transnacional se estabelecer numa cultura local reproduzindo a cultura global. Inspirados no projeto arqueológico de Michel Foucault, construímos um corpus fotográfico de práticas cotidianas de uma marca global. Tal processo se deu por meio de um trabalho de ordenação, definiç̧ão e descrição, elaborado no interior do campo discursivo, pautado nas ações de marketing da marca. A análise nos revelou as formações discursivas entre culturas global e local e nos possibilitou desvelar as relações existentes nessa teia. Os resultados apontaram alguns caminhos para reflexão, tanto acerca da importância assumida pela marca na cultura quanto da forma assumida pelas sociedades ocidentais contemporâneas.

Palavras-chave: Marca global. Cultura local. Discurso. Arqueologia.

\author{
Discursive Formations of a Global Brand in a Locall Context: a studly \\ inspired in Michel Fourcaullt's aurchaeological method
}

Abstract

I

he advent of globalization has generated an entangled field of cross-cultures enabling the establishment of universal values in local media. This context and mass culture have promoted brands to become complex and global cultural symbols. Our aim is to understand how a transnational brand can establish itself in a local culture reproducing a global one. Inspired by Michel Foucault's archaeological project, we constructed a photographic corpus of the daily practices of a global brand. This was done by ordering, defining and describing within the discursive field, guided by brand marketing practices. The analysis revealed the discursive formations between global and local cultures and unveiled existing links in this network. Our results can be used to reflect on both the importance assumed by brands in culture and the form assumed by contemporary Western societies.

Keywords: Global brand. Local culture. Discourse. Archeology.

\footnotetext{
* Mestre em Gestão Empresarial pela Faculdade Boa Viagem - FBV/PE. Professora Assistente do Núcleo de Design da Universidade Federal de Pernambuco - CCA/UFPE - Recife/PE/Brasil. Endereço: Rodovia BR 104, KM 59, Nova Caruaru. Caruaru/PE. CEP 55024-970. E-mail: flaviazimmerle@hotmail.com. ** Doutor em Administração pela UFPE. Professor Adjunto do Departamento de Ciências Administrativas da UFPE - DCA/UFPE - Recife/PE/Brasil. E-mail: aleao21@hotmail.com.
} 
s processos de globalização e mundialização induziram a superação dos espaços hegemônicos de coesão social (ORTIZ, 2007) por meio da produção de um universo simbólico no qual a estrutura da sociedade ocidental foi e permanece exposta e onde se reconstrói de forma sistêmica. O suporte dessas mudanças encontra-se nas condições particulares de formação da modernidade ( SLATER, 2002; MCCRACKEN, 2003; BARBOSA, 2004; ORTIZ, 2007), responsáveis por desencadear a tendência de globalização e suas conflituosas relações entre culturas (ADORNO, 2002; JAMESON, 2002; ORTIZ, 2006; CASTELLS, 2008).

Se, de um lado, esses processos desenraizaram as formas culturais e forjaram no interior da sociedade de consumo as referências culturais globalizadas (ADORNO, 2002; ORTIZ, 2008), de outro, a lógica de produto global pressupôs traçar uma estratégia comercial particular em que o "não-lugar"1 foi articulado acima de toda ordem de fronteiras e particularidades, causando uma [des]ordem espacial global no sistema capitalista mundializado. As marcas globais adotam, para seu fortalecimento no mercado, um posicionamento uniforme e estratégias universais, devido à necessária racionalização administrativa (KAPFERER, 2003; CHEVALIER; MAZZALOVO, 2007). Essa postura conduziu as marcas globais no processo de mundialização e produziu uma lógica "inventada", que se realizou e operou reificação na cultura de massas (ORTIZ, 2007); visando promover a marca ao posto máximo da mundialização, as estratégias apoiaram-se no branding patrocinador de cultura e objetivaram sobrepujar a cultura nativa (KLEIN, 2008).

Foi, desse modo, que a marca transnacional ${ }^{2}$ se valeu da cultura de massas cosmopolita e generalista para compartilhar mundialmente os discursos de seus produtos idênticos. O cenário fértil de formação da modernidade já havia promovido as marcas a uma posição emblemática na estrutura social. Apoiadas em discursos publicitários que buscam, antes de vender produtos, vender sentidos, as marcas viraram o próprio objeto de troca desejado pelos sujeitos e conquistaram um papel fundamental como signos circulantes da vida cotidiana (LEÃO; MELLO, 2004; SEMPRINI, 2006; KLEIN, 2008). Quando assumiram a postura ideológica global, as marcas impuseram a participação no sistema como uma condição de existência, fato que instituiu as relações de conflito entre as culturas, uma vez que envolveu formas de poder nas quais não existe partilha (ADORNO, 2002; ORTIZ, 2007), mas que fez parte da configuração que assumiu a política mundial do novo milênio (EAGLETON, 2005).

Assim, na interação entre as culturas global e local, se instaura e fortalece sempre um conflituoso campo de relações entre poder e resistências. O modelo econômico dominante integra os processos de globalização e mundialização, constrói relações de consumo e gera toda a ordem de consequências que envolvem questões culturais, de conhecimentos e de economia, para culturas inseridas nessa forma social. Porém, esse modelo relacional só se estabelece em um processo dialético entre as culturas, produzindo lógicas próprias de uso e modos de apropriação do que é imposto. Tal fato gera novas construções de sentidos no interior de práticas cotidianas mundanas, criando um complexo campo discursivo que requer entendimento.

Considerando o que foi exposto, como as marcas globais conseguem se estabelecer e reproduzir discursos numa cultura local?

\footnotetext{
${ }^{1}$ Para Marc Augé (2009), alguns espaços podem assumir o papel de não lugares. Segundo suas teorias, contrariamente aos lugares antropológicos, nos não lugares os indivíduos não conseguem estabelecer elos sociais como laços afetivos, identitários, comunitários ou históricos. Os não lugares são espaços de passagem, tais como aeroportos, shoppings, hotéis etc. Para o autor, a supermodernidade é produtora de não lugares.

2 Para Ortiz (2007), o desenvolvimento e a consolidação desse mercado tende a tornar obsoleta a concepção de empresa multinacional, abrindo espaço para a corporação transnacional, em que existe o comprometimento apenas com uma missão global, única e unificada. Os clientes que os interessam são pessoas que apreciam seus produtos em todos os lugares do mundo.
} 
A sociedade ocidental compartilha de um copioso cenário de consumo e uma nova ordem social (BAUDRI LLARD, 2007) que induziu a marca a se tornar uma entidade geradora de valor (SEMPRINI, 2006; LEÃO; MELLO, 2007; KLEIN, 2008).

As características das entremeadas relações do consumo com as culturas ocidentais são o resultado das condições de constituição de seus campos social, cultural e econômico. A possibilidade foi articulada na medida em que instigou a construção do pensamento moderno no entrelaçamento da cultura com o consumo (SLATER, 2002; McCRACKEN, 2003; BARBOSA, 2004), favorecendo, no século XX, a projeção da imagem do modo de vida consumista dos Estados Unidos como um ideal de sucesso e liberdade, o que traçou linhas divisórias entre os então chamados Primeiro e Terceiro Mundos, entre o socialismo e o capitalismo, articulando um sonho de cultura globalizada possível de se dar no sistema de consumo (SLATER, 2002; KLEIN, 2008). Assim, a condição de compreensão da sociedade ocidental tem no fenômeno de consumo um elemento fundamental, ou ainda, um elemento-chave para análise de relações sociais e sistemas simbólicos. Sendo considerado um processo cultural, sua história e desdobramento na multiplicação e na abundância de objetos e seu ascendente papel na vida social fazem do consumo o meio significativo fundamental de expressão e constituição dessa forma social (SLATER, 2002; MCCRACKEN, 2003; BARBOSA, 2004; DOUGLAS; ISHERWOOD, 2006; MILLER, 2006; BAUDRILLARD, 2007).

Nessa conjuntura, a marca tornou-se uma entidade autônoma de comunicação, condição que a impulsionou para a posição de evidência e importância que ocupa no contemporâneo, cuja lógica deve-se justamente "ao cruzamento de três grandes dimensões profundamente imbricadas nos espaços sociais contemporâneos: o consumo, a economia e a comunicação" (SEMPRINI, 2006, p.59). Nesse sentido, a marca transnacional em sua relação com a cultura local representa, também, um importante papel na criação de uma comunicação para os processos sociais orientados pela lógica de mercado: a comunicação pautada na publicidade e na propaganda, as quais transmitem e constroem as interpretações da realidade e do mundo da vida (DEBORD, 1997; HABERMAS, 2002).

Entendemos as marcas como entidades relacionais geradoras de valor de troca e de uso que existem apoiadas em um conjunto de discursos (BROWN, 2006; SEMPRI NI, 2006; LEÃO, 2007). Consideramos que as mesmas trilharam um percurso sígnico de valor. O projeto de marca é um pólo produtor de sentidos que busca ser assimilado por um pólo destinatário que recepciona, interpreta e avalia em que medida este discurso pode contribuir com seus projetos (SEMPRINI, 2006). Assim, para existir e ser reconhecida como discurso social, além de ser signo identificador de valores e diferenciador de produtos e serviços em um mercado competitivo, a marca possui esse valor reconhecido pelos consumidores em situações sociais (LEÃO; MELLO, 2007). Por tratar-se de uma construção social, buscamos compreendê-la e analisá-la segundo princípios que consideram contextualizações amplas a respeito do comportamento do consumidor e que levam em conta a extrema relatividade na liga do que é considerado valor de um produto ou serviço no contemporâneo (BROWN, 1993; COVA, 1997; ROCHA et al., 1999; BARBOSA; CAMPBELL, 2006; MELLO, 2006; SEMPRINI, 2006; LEÃO, 2007; KLEIN, 2008).

Desse modo, por meio da análise arqueológica dos discursos mundanos construídos no intercâmbio entre as culturas global (mecanismos de dominação) e local (dialética que promove as lógicas de uso e apropriação do que foi imposto), foi possível reafirmar a importância assumida pelas marcas nesta cultura, compreender como uma marca global se estabelece e reproduz seus discursos numa cultura local, e ainda gerar insights para compreensão sobre a forma que assumiu a sociedade ocidental contemporânea. A analítica do projeto arqueológico é capaz de revelar a rede formada da inter-relação de diversos saberes instaurados em formações discursivas (FAIRCLOUGH, 2001; FOUCAULT, 2007; THIRY-CHERQUES, 2008). 


\section{Procedirnentos $\mathbb{M}$ extodlológicos}

Esta pesquisa objetivou a compreensão de como é possível uma marca transnacional se estabelecer em uma cultura local e reproduzir a cultura global. Para tanto, nos apoiamos no paradigma interpretativista (DENZI N; LI NCOLN, 1994), e entendemos que a construção e a geração de conhecimentos se efetuam por meio da linguagem. Como o cerne teórico que norteia a nossa investigação é o projeto arqueológico do filósofo Michel Foucault, o foco da pesquisa voltou-se para a estrutura das formações discursivas que ordenam os discursos (as regras de formação que definem os discursos mundanos de marca, suas modalidades enunciativas, sujeitos, conceitos e estratégias discursivas), estando à busca guiada para a compreensão de como essa prática discursiva foi capaz de promover efeitos sobre a construção de saberes naquele tempo/ espaço/contexto. Assim, a análise dos discursos mundanos construídos no intercâmbio entre as culturas local e global busca o desvelar das regras a que esses discursos estão sujeitos (FOUCAULT, 2007; THIRY-CHERQUES, 2008).

O plano de pesquisa constituiu-se do método de observação direta e coletou os dados pelo recurso fotográfico. Essa definição para a coleta de dados primários deveu-se ao fato da marca se utilizar amplamente do recurso de expressividades imagéticas para seu posicionamento nos mercados alvo. Desse modo, o processo de observação não esteve vinculado a nenhum outro método. Os registros visuais ${ }^{3}$, ao invés de estarem na condição de suporte secundário, assumiram aqui o principal registro de campo (BARBOSA, 2004; BONI; MORESCHI, 2007), e o roteiro de observação do processo investigativo seguiu os princípios norteadores gerais recomendados para estudos qualitativos e para investigações arqueológicas nas etapas de observação e análise dos dados (GODOY, 2006; THIRY-CHERQUES, 2008).

A fotografia ${ }^{4}$ foi explorada como uma forma de narrativa, tendo essa estrutura possibilitado o entendimento de como os significados são construídos, incutidos e veiculados nos meios sociais, obtendo modos singulares de observar e descrever a cultura e as modificações provocadas em seu meio (CAVEDON, 2001; ACHUTTI; HASSEN, 2004; HARPER, 2005; BONI; MORESCHI, 2007).

Contudo, devido ao ilimitado campo de criação de sentido pertinente ao recurso selecionado (GODOI; BALSANI, 2006; GODOY, 2006), a subjetividade foi preservada pelo uso da analítica interpretativa arqueológica e pela adoção de um planejamento da ida ao campo. Organizamos um fotograma baseado num programa de guarda e gerenciamento de imagens, que preservou a recuperação por sequências e por temática de imagens, propiciando que os resultados das séries gerassem uma narrativa (ACHUTTI; HASSEN, 2004; BONI; MORESCHI, 2007), tendo em vista que a proximidade espacial das cenas foi a condição determinante para formação das séries discursivas.

Para esta pesquisa, foi definida uma marca representante da cultura global - a Coca-Cola - e sua presença na cultura local: a Região Metropolitana da cidade de Recife. Esta, por ser uma cultura que compartilha da condição de sociedade ocidental, e aquela, por se constituir um produto emblemático da sociedade de consumo mundializada. O corpus foi formado por registros de cenas do cotidiano que comunicavam a marca

\footnotetext{
${ }^{3}$ Os registros visuais são um meio poderoso de capturar ações temporais de acontecimentos reais; podem ser empregados como dados primários para pesquisa sociais não necessitando de outras informações, podendo ser uma forma de registro indicada nesse momento em que o mundo é crescentemente influenciado pelos meios de comunicação e os resultados dependem de elementos visuais. Esses elementos se tornaram "fatos sociais" (LOIZAS, 2002).

${ }^{4}$ As imagens fotográficas, sendo uma dimensão da lingüística, são entendidas como uma forma de texto que pode ser lido e decodificado, uma vez que o trabalho esteve pautado em estudos da cultura material em uma perspectiva pós-estruturalista. A mais importante influência pós-estruturalista pode ser rotulada de "textualização" e caracteriza os novos modos de ler e analisar os textos. O conceito de "textualização" inclui uma lógica sobre como as coisas se transformam em discurso escrito, que está associado a uma epistemologia de leitura que desafiou as instalações interpretativas existentes, sendo marcada pelo sacrifício do autor e da estrutura (FOUCAULT, 2007; OLSEN, 2006). Considerando que o leitor é o produtor de sentidos, a epistemologia de leitura envolve uma ruptura ontológica, uma vez que o texto não pode ser separado do contexto, ou seja, não existe possibilidade de vida fora do intertexto (FAIRCLOUGH, 2001; FOUCAULT, 2007; THIRY-CHERQUES, 2008), assim como não existe significado fora do jogo da diferença, da alteridade.
} 
Coca-Cola, selecionados por representatividade e presença no espaço pré-determinado de pesquisa. A pesquisa teve a duração de sete meses e resgatou um total de 773 imagens. Após as primeiras experiências em campo, sistematizamos a coleta: a região foi subdividida em áreas geográficas, nas quais foram traçados um cronograma de atuação e as sequências de rotas a serem percorridas e; utilizamos no percurso das rotas o GPS - Global Positioning System ${ }^{5}$, interligado ao equipamento fotográfico, visando ao resguardo das informações geográficas formadoras das séries discursivas, o que além de facilitar a localização dos registros, permitiu gerar os mapas com as trilhas demarcadas ${ }^{6}$ e as distancias percorridas. Essas informações foram extraídas utilizando o serviço do Google Maps?.

Para o uso da analítica arqueológica, foi necessário desenvolver um caminho metodológico tanto para as observações, quanto para a análise dos dados obtidos em campo. A identificação dos registros foi efetuada tendo por base corpo de conhecimentos do composto de marketing e seu conjunto de ferramentas, uma vez que estes orientam e representam as ações da marca (KOTLER, 2000), e a análise discursiva não buscou interpretar o documento em si, mas trabalhar em seu interior, ordená-lo, definir suas unidades e descrever suas relações, compondo o processo arqueológico (FOUCAULT, 2007).

A busca foi por localizar os signos da marca, tanto nas ações de marketing específicas referentes a preço, praça, promoção e produto que se encontravam disponíveis nos cenários (comunicação oficial da marca), quanto nas práticas mundanas que se estabeleceram de forma espontânea por meio deles. Devido à diversidade de saberes presente nesse campo discursivo, a seleção das cenas seguiu o seguinte roteiro: 1) os elementos da marca precisavam estar representados; 2) a cena identificada deveria ser promovida oficialmente pela marca ou pelo uso de seus signos; 3 ) nas ocasiões em que não se apresentaram os sinais evidentes da marca (nome e logo), seria preciso que a cena pertencesse a um contexto enunciativo de voz ativa da marca; 4) em praças não "oficiais", seriam considerados no cenário apenas os elementos do contexto que pertenciam à mesma classificação do enunciado da marca que foi identificado, de modo a promover a prática comparativa.

Na primeira fase da análise, surgiu dos discursos a formação das séries enunciativas, seguida das unidades discursivas e da identificação de suas funções específicas. A organização dos dados de campo revelou as funções de cada elemento no interior dos enunciados, que se deu a partir da análise de suas relações com o contexto e domínio a ele associado. A compreensão das funções foi embasada pela literatura de marketing, na qual consultamos os seguintes autores: Aaker, 2000; Kotler, 2000; Shimp, 2002; Kapferer, 2003; Perez, 2004; Brown, 2006; Semprini, 2006; Chevalier e Mazzalovo, 2007; e Klein, 2008; e pelas relações da cultura de consumo, aqui embasadas por Slater, 2002; McCracken, 2003; Barbosa, 2004; Douglas; Isherwood, 2006; Miller, 2006; e Baudrillard, 2007.

Assim, na medida em que o quadro formado por descrições enunciativas e suas respectivas funções foi se constituindo, tornou-se possível identificar que as práticas

${ }^{5}$ O GPS é um sistema de localização de posicionamento de um receptor na superfície da terra a partir de sinais emitidos por satélite. O receptor decodifica as transmissões de sinais de múltiplos satélites e calcula a posição exata (latitude, longitude e altitude) com base nas distâncias destes.

${ }^{6} \mathrm{O}$ fato de precisarmos registrar imagens em lugares afastados e desprovidos de sinalização representou uma grande dificuldade, tendo em vista que, em nossa pesquisa, a localização geográfica foi fundamental para a formação das séries discursivas, tornando o mapa uma ferramenta indispensável para ida ao campo. Inicialmente, o tempo gasto para localização ameaçou inviabilizar o cumprimento das rotas na programação do cronograma, pois ainda tínhamos o agravante das imagens necessitarem da claridade do sol para seu registro. Contudo, no momento em que sistematizamos a coleta, optamos por utilizar o GPS interligado à máquina fotográfica, condição que agilizou o processo e simplificou a coleta da pesquisa.

${ }^{7}$ A decisão de utilizar equipamentos profissionais foi determinante para realizarmos a coleta no tempo que nos propomos (sete meses de imersão no campo) e, ainda, para cumprir o critério espacial determinante para as séries discursivas da pesquisa. Contudo, essa escolha propiciou falhas em relação à nitidez e enquadramento das imagens que, por vezes, precisaram ser registradas no interior do veículo por questões de segurança da pesquisadora, uma vez que a cidade em que foi realizada possui altos índices de violência e o equipamento profissional chamava muita atenção. 
discursivas são regidas por regras que estabelecem transformações e encadeiam descontinuidades. Essas regras que regulam e governam os atos discursivos trazem o sentido para as funções. Desse modo, o procedimento foi composto de três componentes analíticos: as descrições enunciativas (compostas de signos da marca), que possuem uma função (apresentam uma finalidade no contexto da cena) que, por sua vez, obedece a regras de funcionamento (que são partilhadas). Com base na elucidação e posterior triangulação desses três aspectos, foram desveladas as formações discursivas. A elucidação da articulação e ordenação dessa estrutura foi o que permitiu analisar os discursos deste intercâmbio.

\section{A Orderm dlo Discrurso}

A analítica arqueológica busca descrever como se constitui um campo discursivo, qual seja, uma rede formada pela inter-relação de diversos saberes. Para Foucault (2007), o saber inclui, além dos conhecimentos formais, as instituições e práticas de atividades do conhecimento não formal, tais como as percepções e saberes não científicos. A emergência dos discursos surge dessa rede e de suas características específicas ( FAIRCLOUGH, 2001; FISCHER, 2001; FAE, 2004; EIZIRIK, 2006; FERREIRA, 2006; PIMENTEL; VASCONCELOS, 2007; THIRY-CHERQUES, 2008). Assim, a investigação se dá sobre a estrutura das formações discursivas, ou seja, a análise não é realizada no sentido de buscar o que o enunciado quer significar, mas, sim, constituiu um descobrimento, uma elucidação trazida à tona através da rede de interligações formada pelo dispositivo. O discurso deve sempre ser revelado enquanto prática que obedece a regras (FOUCAULT, 2007; THIRY-CHERQUES, 2008). Por essa razão, ao invés de procurar fazer interpretações desses enunciados, buscamos fazer aparecer "as ideias, os ideais, os conceitos, mas, também, os sentimentos, os instintos, a filosofia" (THIRY-CHERQUES, 2008, p. 232) sociais que, no presente trabalho, se entrelaçam nos discursos contemporâneos entre a civilização ocidental e a marca global.

Uma formação discursiva, para Foucault (2007), é um conjunto formado por enunciados, conceitos e escolhas temáticas que descrevem um sistema de dispersão. Os sistemas de dispersão encontram-se nas diversas possibilidades estratégicas de discursos, as quais permitem a ativação de temas que são incompatíveis, ou, ainda, na introdução de um mesmo tema em conjuntos diferentes. Os conjuntos surgem para o pesquisador quando o mesmo efetua a interseção gráfica entre as linhas percorridas nos três níveis (dispostos em forma de colunas) previamente descritos (descrições enunciativas, funções e regras), ou seja, o conjunto representa uma combinação específica pertinente a cada formação discursiva.

Um enunciado constitui-se de um conjunto de signos considerados no nível de sua existência, ou seja, esse conjunto possibilita um saber. A descrição dos enunciados do campo discursivo constituiu-se a unidade enunciativa desta pesquisa. Em nossas rotas, identificamos como enunciado as ações específicas de marketing realizadas nos pontos de venda e verificamos que cada enunciado foi formado por um conjunto de elementos (constituintes do valor da marca), sendo, por meio de suas funções assumidas nesse conjunto, que este gera sentido àquele. As descrições enunciativas são apresentadas no Quadro 1.

\section{Quadro 1 - Descrições Enunciativas}

\begin{tabular}{|l|l|}
\hline \multicolumn{1}{|c|}{ Denominações } & \multicolumn{1}{c|}{ Composição da descrição do enunciado } \\
\hline Elementos da logomarca & Signos da marca - nome, representação da onda, grafia e cores \\
\hline Peças publicitárias & $\begin{array}{l}\text { Toda mídia externa - outdoor, faixa e painel. Por exemplo: a } \\
\text { peça 'O melhor sabor de Pernambuco' e suas variações, tanto na } \\
\text { fachada de PV, como em forma de painel na frota de distribuição } \\
\text { ou, ainda, no centro da cidade, guarnecendo a parada de ônibus } \\
\text { e a placa de pedestres nas margens do Centro de Excelência. }\end{array}$ \\
\hline Material de merchandising & $\begin{array}{l}\text { Sinalizações de preço, promoções de ponto de vendas e selo } \\
\text { (CAC ou comemorativo). }\end{array}$ \\
\hline
\end{tabular}




\begin{tabular}{|l|l|}
\hline Pontos de atendimento & $\begin{array}{l}\text { Centro de Excelência, Estação de Reciclagem Coca-Cola e ação } \\
\text { de prestação de serviço de utilidade pública efetuada por meio } \\
\text { da marca. }\end{array}$ \\
\hline Ações promocionais & $\begin{array}{l}\text { I magem dos produtos de promoção, título das campanhas e } \\
\text { ações como: estipular regras para a participação das mesmas e } \\
\text { condições programadas de ambiente para viabilizá-las }\end{array}$ \\
\hline $\begin{array}{l}\text { Cohabitação com marcas } \\
\text { concorrentes }\end{array}$ & $\begin{array}{l}\text { Presença da concorrência - signos da multimarca, signos de ou- } \\
\text { tra marca ou produto, sinalização de preço de outra marca ou } \\
\text { produto, promoção de outra marca ou produto. }\end{array}$ \\
\hline Operações do distribuidor & $\begin{array}{l}\text { Signos do distribuidor, jogo eletrônico, churrasco, som e televi- } \\
\text { são, ambiente (coberta choupana ou palha), estoque da marca, } \\
\text { estoque de outras marcas ou produtos, lista de iguarias, promo- } \\
\text { ção conjunta marca/ distribuidor, tíquete refeição e/ou cartão de } \\
\text { crédito, frota de distribuição como caminhão e moto, presença } \\
\text { da bicicleta ou do carro de mão para entrega. }\end{array}$ \\
\hline Adaptações populares & $\begin{array}{l}\text { Adoção de outras cores, título da peça da marca adaptado por } \\
\text { outrem, nome próprio, nome alusivo ao negócio, nome alusivo à } \\
\text { localização ou à crença, nome (guaraná, fruta, caldo de cana), } \\
\text { candidato político, pichação, ambulante, bicicletas e carro de } \\
\text { mão com o produto, revelar regras, fazer votos ou apelo contra } \\
\text { violência por meio da marca. }\end{array}$ \\
\hline
\end{tabular}

Na prática enunciativa desta investigação, a função constituiu uma ação que se revelou por meio da existência de um domínio de saberes que lhes está associado: as relações da cultura de consumo e o campo teórico do marketing. Localizar a função representou uma operação de decifração que buscou revelar a ação que cada elemento do enunciado propicia no contexto discursivo. O Quadro 2 apresenta as funções encontradas e suas respectivas descrições.

\section{Quadro 2 - Funções Enunciativas}

\begin{tabular}{|l|l|}
\hline \multicolumn{1}{|c|}{ Nome } & \multicolumn{1}{c|}{ Ação propiciada } \\
\hline Antropomorfizar & Atribuir qualidades humanas aos signos da marca \\
\hline Apoiar convenção social & Comunicar convenção social por meio da marca \\
\hline Apropriar-se de aspectos culturais & $\begin{array}{l}\text { Apropriar-se intencionalmente de aspectos culturais na- } \\
\text { tivos }\end{array}$ \\
\hline Comunicar & Desenvolver os elementos da marca \\
\hline Desculpabilizar excesso & Indicar combinação para atenuar o excesso calórico \\
\hline Estipular regras & Estipular regras para participar de promoção da marca \\
\hline Experienciar & Criar condições de usufruto da experiência da marca \\
\hline Identificar parceiros & Identificar parceiros comerciais \\
\hline Identificar-se & Promover a identificação da marca \\
\hline Incorporar aspectos culturais & Assimilar aspectos culturais por meio da marca \\
\hline Persuadir & Levar a crer nas promessas da marca \\
\hline Promover hegemonia & Tornar preponderante o discurso da marca \\
\hline Propiciar entretenimento & Apoiar ou promover ações de entretenimento \\
\hline Tolerar diferenças estéticas & $\begin{array}{l}\text { Tolerar a não adoção do padrão estético (cor/forma) esti- } \\
\text { pulado pela marca }\end{array}$ \\
\hline Tolerar partilhamento do espaço & $\begin{array}{l}\text { Dividir o espaço com outras marcas, inclusive de concor- } \\
\text { rentes }\end{array}$ \\
\hline Ser representada & $\begin{array}{l}\text { Ter seus signos assimilados pelos signos de outrem (pa- } \\
\text { rasitas culturais) }\end{array}$ \\
\hline
\end{tabular}


Como a regra é uma prática social (FOUCAULT, 2007), o uso que gera sentido aos signos precisam ser delimitados e definidos na especificidade de cada forma de vida. Nesta pesquisa, a regra é uma prática social mediada pela marca. As regras foram estabelecidas na condição de existência e permanência dos elementos em cada repartição discursiva. No Quadro 3, buscamos nas séries discursivas as condições de [co] existência, manutenção, modificação ou desaparecimento dos elementos que compõem os enunciados.

\section{Quadro 3 - Regras de Uso}

\begin{tabular}{|l|l|}
\hline \multicolumn{1}{|c|}{ Nome } & \multicolumn{1}{c|}{ Descrição } \\
\hline Uniformidade & $\begin{array}{l}\text { Emprego padronizado dos elementos de marca no processo de comu- } \\
\text { nicação }\end{array}$ \\
\hline Reprodução & A repetição contínua das mensagens da marca \\
\hline Articulação cultural & Interação entre a marca e a cultura local \\
\hline Polifonia & $\begin{array}{l}\text { Associação da marca com outros planos discursos (endosso, co-bran- } \\
\text { ding etc. }\end{array}$ \\
\hline Incitamento & Instigar vinculação com promessas da marca \\
\hline Prática do poder & Influenciar o comportamento de outrem por meio da marca \\
\hline Rebeldia & Cometer ação de transgressão por meio da marca \\
\hline Relação de poder & $\begin{array}{l}\text { Estabelecer relações de confronto (disputa) entre a marca e outros } \\
\text { discursos (por meio de concorrência direta ou indireta do espaço; pi- } \\
\text { chações etc) }\end{array}$ \\
\hline Redundância & Facilitar a recepção e interpretação das mensagens por meio da marca \\
\hline Credibilidade & Garantir disponibilização do serviço \\
\hline
\end{tabular}

No campo discursivo, identificamos que as relações entre as culturas global e local podem ser ordenadas em: relações de agência, que representam os discursos disciplinares provenientes da marca (representantes da postura ideológica global); relações que se estabelecem por confronto, nas quais estão locados os discursos que se estabelecem por indisciplina; ou, ainda, relações caracterizadas por associação entre as partes, que se deu por síntese. Assim, as formações discursivas reveladas por disciplina estabelecem e ordenam o sistema discursivo agenciado pela comunicação da marca. Por meio destas, são promovidos uma série de outras formações que se filiam às mesmas, se tornando formação por síntese, ou promovem conflito por se apossarem da mesma (parasitas culturais), ou, ainda, se conflitam com ela por competirem pelo mesmo espaço discursivo, se estabelecendo por indisciplina. Seguem abaixo as oito formações discursivas desveladas nesse campo.

\section{Iogo de mennỏrial}

As funções que coexistem e integram as regras denominadas reprodução e uniformidade são provenientes das mesmas descrições enunciativas (elementos da logomarca, peças publicitárias e materiais de merchandising) que constituem a comunicação da marca. Esse conjunto de descrições apresenta por função: identificar-se, comunicar, promover hegemonia e persuadir. Na llustração 1 é possível observar que essas regras se apresentam como discursos interdependentes por se integrarem para representar a marca em seu meio discursivo.

A uniformidade e a reprodução promovem a construção da memória imagética do consumidor e a consequente familiaridade com os signos da marca (ADORNO, 2002), trazendo para essa formação discursiva uma ordem sistêmica: transmissão uniforme e repetida que, juntamente com a distribuição de objetos idênticos, favorece que o consumidor estabeleça em sua memória uma série de associações desejáveis da imagem da marca. Esse conjunto de ações fortalece o discurso persuasivo da marca (KAPFERER, 2003). Desse modo, a prática discursiva global busca gerar um acervo de memórias por meio de um jogo estratégico e articulado de comunicação da marca 
( postura ideológica) com a cultura e o usuário local, estabelecendo para essa formação discursiva a denominação de jogo de memória.

\section{I lustração 1 - Série de Pontos de Venda I nformais Patrocinados pela Marca ao Longo de uma Avenida de Grande Movimento}

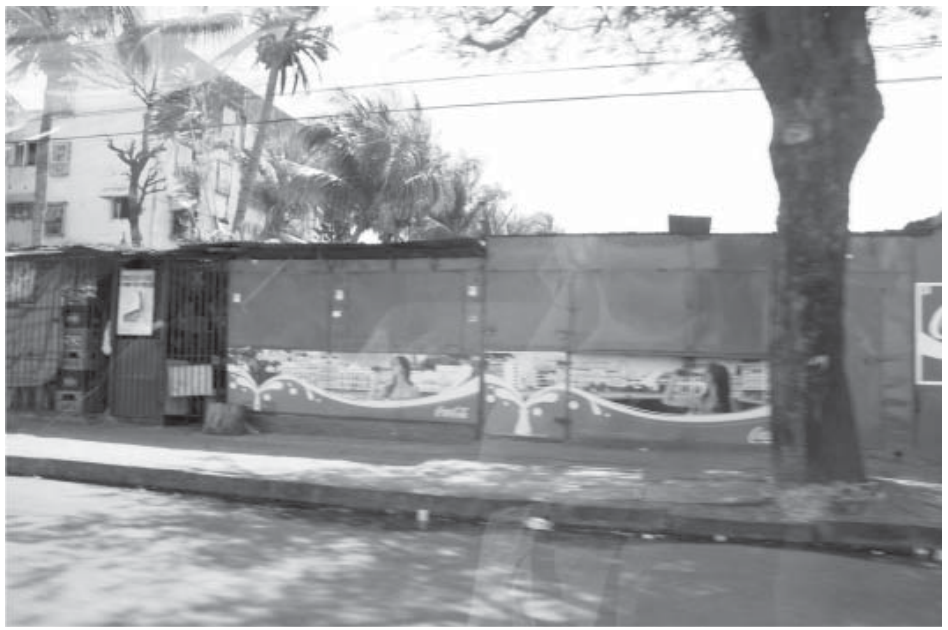

Fuñções dlo marlketing

As regras credibilidade e incitamento representam duas das funções do marketing. As mesmas fazem parte do plano de marketing para a marca, ou seja, da programação das várias atividades que são destinadas sistematicamente para criação e manutenção de sua identidade do mercado (SANT'ANNA, 2002). Na interseção dessas regras, identificamos que operações com o distribuidor é a única descrição enunciativa que integra ambas as regras. No incitamento, essa descrição corresponde a promoções feitas com o distribuidor, que tem por função persuadir. Na credibilidade, a mesma apareceu sob as formas de tíquete refeição, cartão de crédito, presença na frota de caminhões de distribuição ou, ainda, estoque da marca, as quais visam facilitar e garantir 0 atendimento.

\section{I lustração 2 - Pontos de Venda Padronizados Patrocinados pela Marca em Terminal de Ônibus no Centro da Cidade}

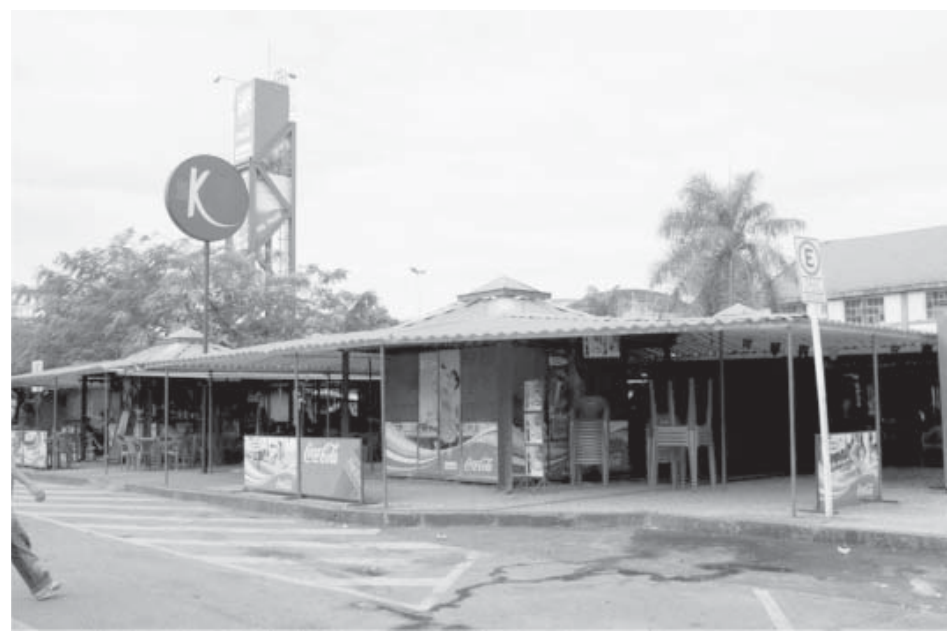


A função comunicar é comum a ambas as regras, embora estas tenham aparecido por meio de descrições enunciativas diferentes: na regra incitamento, a função provém dos pontos de atendimento encontrados no campo; na credibilidade, estão ligadas a operações com distribuidor e material merchandising. Conforme pode ser visualizado na l lustração 2, a marca apresenta-se de forma expressiva no ponto de atendimento.

Essa expressividade, ao mesmo tempo em que garante o atendimento, reforça ou endossa as promessas da marca (AAKER, 2000). Tais descrições enunciativas e suas funções constituem os instrumentos que subsidiam o plano de marketing da marca, ou seja, as mesmas dão embasamento às regras que fazem parte das funções do marketing, razão da denominação desta formação discursiva.

\section{Marniprulação e confironto}

A regra prática de poder caracteriza a busca de influenciar o comportamento de outrem por meio da marca, utilizando, para tanto, de persuasão; a regra relação de poder caracteriza as relações de confronto estabelecidas na busca pelo espaço discursivo entre a Coca-Cola e outras marcas. Desse modo, enquanto, na primeira regra, a marca é mediadora da manipulação, na segunda, a mesma é objeto de confronto discursivo. Essas regras se apresentam divergentes em quase todas as suas funções e descrições, com exceção de ser representada, comum a ambas. As descrições ligadas à função ser representada são, também, as mesmas: elementos da logomarca e adaptações populares. Contudo, adaptações populares, também, se encontram ligadas a persuadir, na linha da regra prática de poder, e a tolerar diferenças estéticas, na linha da regra relação de poder. Elementos da logomarca buscam, ainda, propiciar entretenimento e persuadir, na linha da regra prática de poder, e apenas ser representada, na linha da regra relação de poder. Na llustração 3, duas fotos estão colocadas lado a lado para representar a situação real em que se encontravam dispostas em três pontos de venda em sequência numa mesma calçada - os dois primeiros podem ser visualizados na primeira foto e o terceiro na segunda.

\section{I lustração 3 - Pontos de Venda I nformais Patrocinados pela Marca, I ntercalados com Pontos não Patrocinados ou Patrocinados pela Concorrência}
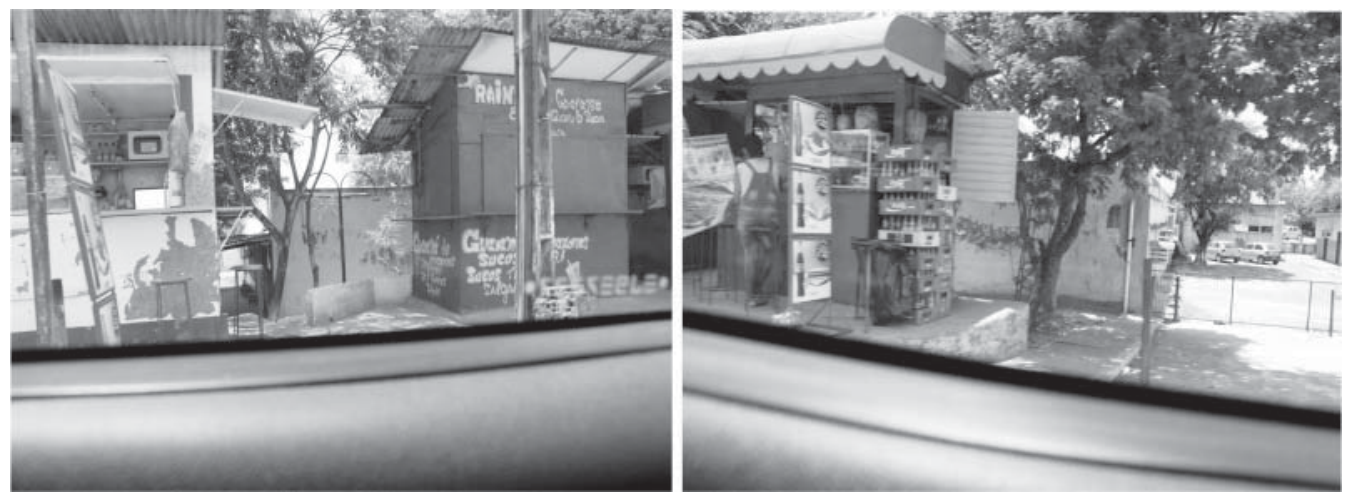

A regra prática de poder representa as diversas práticas populares e ações da marca, assume várias formas de descrições enunciativas, bem como ativa um conjunto variado de funções para seus enunciados. Contudo, a função persuadir é uma constante em todos os enunciados. A regra relação de poder representa o confronto das diversas vozes na disputa do campo discursivo, entre elas: os parasitas culturais, os concorrentes, as adaptações e as operações do distribuidor. Na Ilustração 3, a Rainha do Guaraná encontra-se no centro de duas bancas oficiais, adota as mesmas cores da marca e se insere no contexto discursivo promocional de vendas. Por meio das figuras, observa-se que a marca emprega uma quantidade grande de recursos (descrições enunciativas) ligados a uma série de funções na busca da prática de po- 
der, ou seja, utiliza da manipulação discursiva, que se dá sempre por persuasão. Essa regra encampa, majoritariamente, a voz da marca por meio das descrições: peças publicitárias, pontos de atendimento, ações promocionais, material merchandising e elementos da logomarca, embora esta seja, também, uma função das demais vozes desse campo discursivo. Diferentemente, na relação de poder, os elementos da logomarca estão representados pela voz de parasitas culturais, concorrentes, adaptações e operações do distribuidor, os quais promovem tolerar partilhamento de espaço e diferenças estéticas, numa operação de confronto com a marca.

Divergêncial cullturrall

As regras incitamento e articulação cultural promovem a formação discursiva denominada divergência cultural. Por meio da Ilustração 4, é possível observar que entre as regras existem duas funções enunciativas comuns: peças publicitárias e operações com o distribuidor. A primeira liga-se à articulação cultural, buscando apropriar-se de aspectos culturais, e ao incitamento, propiciando entretenimento. A segunda liga-se à articulação cultural, buscando incorporar aspectos culturais, e ao incitamento, por meio da persuasão.

Nesse caso, o confronto entre as culturas se dá, exatamente, na comparação feita entre os elementos que não se enquadram na área de interseção das figuras, ou seja, entre as regras são incomuns as descrições enunciativas pontos de atendimento ( voz ativa da marca), pertencentes ao incitamento, e adaptações populares na articulação cultural. Enquanto os pontos de atendimento buscam comunicar elementos da marca, adaptações populares buscam antropomorfizar, ou seja, comunicar a cultura local por meio da atribuição de qualidades humanas aos signos da marca. Seguem, também, para outras linhas: incorporar aspectos culturais e apoiar convenção social, com o mesmo intuito de comunicar a cultura nativa, caracterizando a dissensão, como pode ser visualizado na Ilustração 4 .

\section{I lustração 4 - Pontos de Venda Populares Patrocinados pela Marca versus Painel Promocional em Praça de Alimentação Popular no Centro da Cidade}

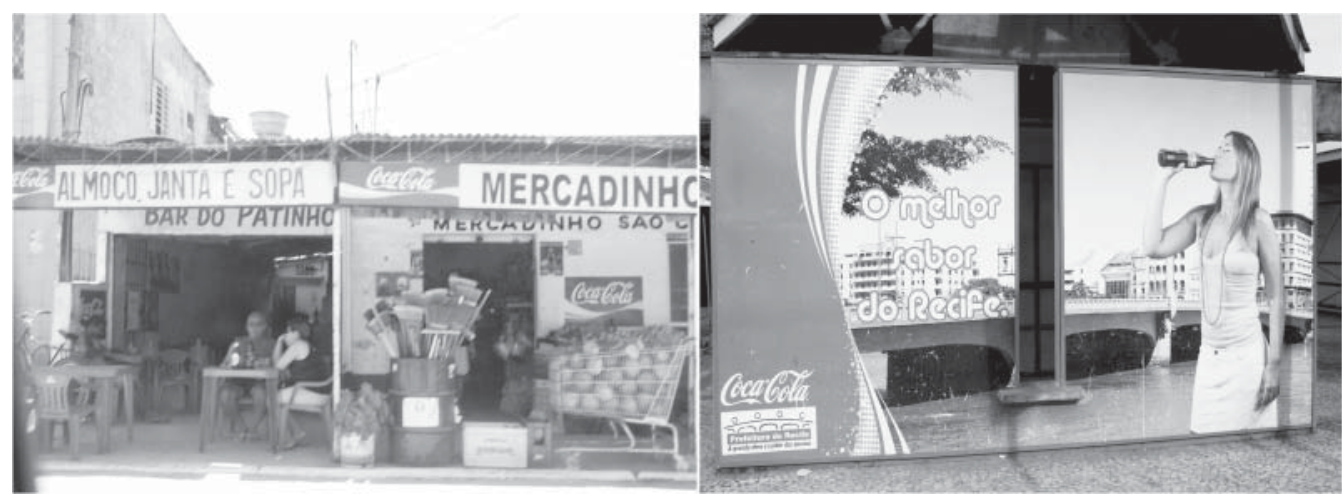

Unm meio dle expressão

As regras rebeldia e articulação cultural apresentam uma única descrição enunciativa comum entre elas: adaptações populares. Essa descrição tem por regra ser representada (assume o papel de parasita cultural) quando ligada à regra rebeldia. Por outro lado, quando adaptações populares se encontram ligada à articulação cultural, esta é representante de ações realizadas por meio da marca que imprimem nas mesmas as marcas da cultura nativa, conforme pode ser visualizado na Figura 6.

Por outro lado, percebemos, na comparação, que o discurso da marca se interessa pela aproximação com a cultura, e o faz apoderando-se de suas características 
e, promovendo a aproximação, torna válida sua prática persuasiva (ver Ilustração 6). A marca promove a postura ideológica da cultura global em sua comunicação e a colônia imprime sua marca, também, por meio dela. A cultura nativa vira instrumento da elocução global na ação da linguagem estratégica (HABERMAS, 2002), mas adota o mesmo jogo de linguagem para se fortalecer. Assim, as culturas (local e global) buscam fortalecer seus discursos, na zona de confronto, utilizando as mesmas estratégias. Por terem motivos antagônicos, essa formação foi denominada de divergência cultural.

\section{I lustração 5 - Propaganda de Outdoor Elaborada com Apropriação de Signos da Marca}

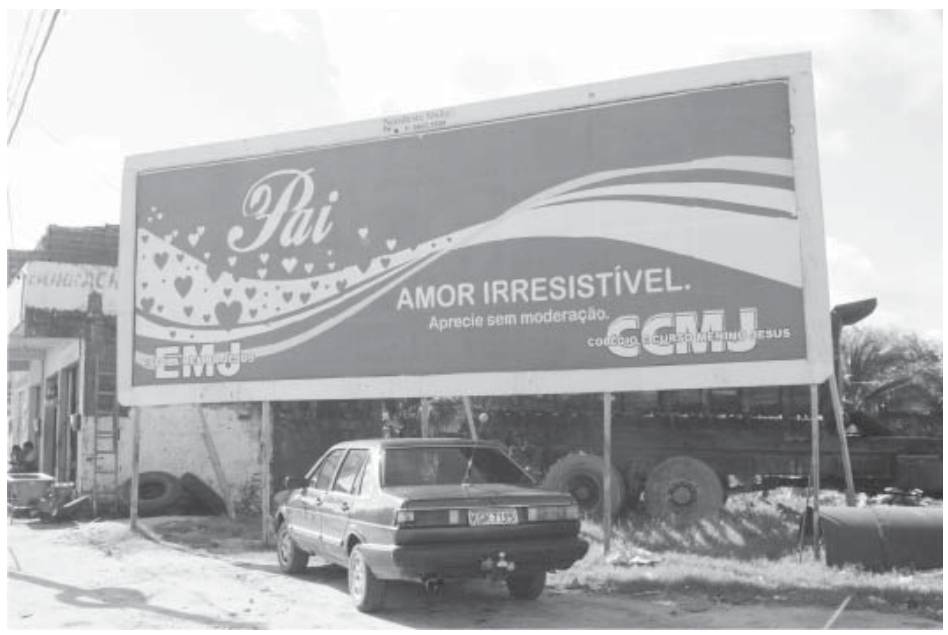

Assim, por rebeldia, as adaptações populares buscam os signos da marca para cometer ações de transgressão. Na articulação cultural, as adaptações populares buscam firmar a cultura nativa adotando nomes próprios para os pontos de venda, incorporar aspectos culturais utilizando expressões de crenças e, ainda, apoiar a convenção divulgando as regras acordadas tacitamente no contexto da convivência social. Ambas as regras utilizam a marca como mediadora de suas ações, ou seja, a marca é um meio de expressão, condição que deu o nome a essa formação discursiva. A atitude nos permite perceber uma situação que representa o conflito global /local, em que a cultura nativa imprime sua marca no cenário, tendo a marca global por mediadora, seja de forma disciplinada (utilizando a mesma estratégia) ou indisciplinada (demarcando a cultura nativa). A cultura como a esfera das representações do vivido (DEBORD, 1997) demonstra sua resistência por meio da persistência ou da indignação.

Srrjeito dlo projeto/Projeto dlo sujeito

Nas regras incitamento e rebeldia, a primeira corresponde à ação promovida com intuito de instigar vinculação com promessas da marca, enquanto a rebeldia é a ação de transgressão efetuada por meio da marca. A regra incitamento foi encontrada nas expressividades da comunicação da própria marca, por meio das peças publicitárias, operações com distribuidor e pontos de atendimento. Nas peças publicitárias, a sua função foi propiciar entretenimento, uma estratégia que faz parte do fortalecimento da imagem da marca. Nos pontos de atendimento, a função buscou comunicar os elementos da marca e, nas operações com o distribuidor, buscou persuadir, ou seja, levar a crer nas promessas da marca. Desse modo, tal forma de discurso constitui- se falaciosa, pois encampa a tentativa de dominação ideológica sobre o receptor, a respeito de sua associação ao ilusório mundo da marca e sua comunidade imaginada, cujas referências são compartilhadas nesta sociedade.

A regra rebeldia, por sua vez, tem por função a busca de ser representado, sendo uma prática exclusiva da descrição enunciativa adaptações populares, em sua 
ação parasitária de comunicação por meio dos signos da marca. Nessa formação discursiva, os discursos mundanos utilizam os signos da marca para cometer ações de transgressão, numa atitude de indisciplina. Existe entre esses níveis intertextuais uma relação: no incitamento, a voz ativa é sempre a da marca e busca instigar, por meio de seu discurso, vinculação de seus signos com suas promessas, fortalecendo e difundindo sua imagem; enquanto isso, na forma parasitária, a rebeldia se apropria desse valor construído socialmente para cometer atos de transgressões e chamar atenção sobre si mesmo. O recurso utilizado demonstra a força do sistema. Em tal formação, encontramos duas vozes e uma sociedade que se apresenta dependente das regras econômicas. Segundo Debord (1997, p. 52), “o sujeito só pode emergir da sociedade, isto é, da luta que existe nela mesma". A llustração 5 é reveladora desses aspectos.

\section{Ideologiar}

Quando as diversas vozes recolhidas no campo discursivo foram acopladas por grandes categorias, pudemos identificar a existência de quatro grupos: a voz da marca, representada pelas seguintes descrições enunciativas: elementos da logomarca, peças publicitárias, material merchandising e ações promocionais (vide Ilustr. 4); a voz do distribuidor, que aparece na descrição enunciativa operações com distribuidor, e lhe representam por meio das ações promovidas na disponibilização do produto (vide llustr. 3); a voz da concorrência, que aparece na descrição enunciativa cohabitação com marcas concorrentes (vide Ilustr. 2); e a voz dos saberes informais, representada pela descrição adaptações populares (vide Ilustr. 5). Quando observadas dessa forma, identificamos que a única função comum a todas as vozes foi persuadir. Assim, por representar a natureza que é inerente a todos os seres discursivos desse campo, denominamos tal formação discursiva de ideologia, por ser uma base de pensamento social que segue uma lógica, a qual foi recortada do real pela ideologia, propiciando uma consciência deformada da realidade (DEBORD, 1997).

\section{I lustração 6 - Ponto de Venda com Polifonia de Marcas}

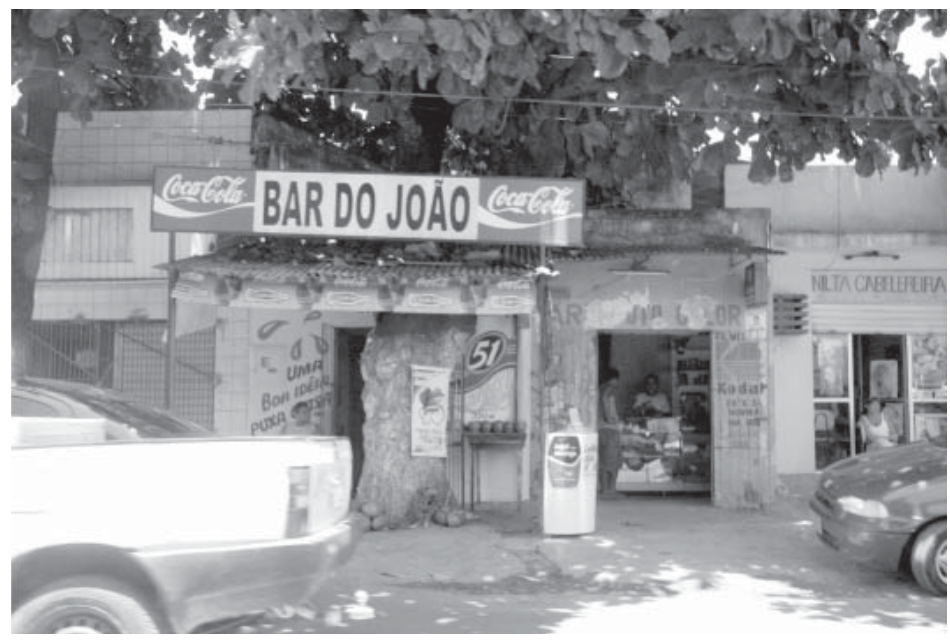

Simbiose

As regras polifonia e redundância possuem por função comum identificar parceiros comerciais. Na redundância, a descrição enunciativa adaptações populares busca, por meio da marca, facilitar a recepção e interpretação das mensagens. Na polifonia, apesar de existir outra função (tolerar partilhamento de espaço), que aparece ligada à cohabitação com marcas concorrentes, a marca, por meio dela e das operações com o distribuidor, se associa com outros planos discursivos para endosso ou co-branding. 
Entendemos que os conjuntos de descrições enunciativas regidos pelas regras redundância e polifonia, que têm por função identificar parceiros, representam um acordo vantajoso para os organismos (as partes da praxe social). Essa formação discursiva foi denominada de simbiose, por representar a associação de seres vivos que vivem em sistema comum, por meio da adoção de estratégias também comuns. Na Ilustração 6 se encontra um exemplo dessa formação discursiva.

\section{Comsidleratções Firmais}

Para a análise reflexiva que nos trouxe às formações discursivas, nos deixamos conduzir pela busca de entendimento de como é possível a relação entre as culturas global e local. Nesse sentido, identificamos que a grande possibilidade se encontra no próprio formato de sociedade, cuja comunicação é capaz de canalizar correntes de informação que dirigem o comportamento social.

A sociedade global fortaleceu as marcas e seus projetos de sentido pautados na comunicação universalista, responsável por gerar a exploração econômica e a dependência cultural entre os mundos da vida e do sistema. Essa inter-relação discursiva fez aflorar novas formas de poder que operam como agentes nas culturas. No formato, o mundo do sistema traça uma estratégia racional com relação a um fim (gerar negócios) e adota interações dirigidas por meios (estratégias de comunicação e geração de experiências). A marca, enquanto representante desse sistema, se estabelece por meio de uma transmissão planejada, acompanhada de uma linguagem estratégica - recheada de imperativos - uniforme e repetida, que comunica valores e formas de interação, explorando o universo particular dos indivíduos e simulando uma proximidade com a cultura nativa. Essa comunicação é pautada na publicidade e na propaganda, as quais transmitem e constroem as interpretações da realidade e do mundo da vida (DEBORD, 1997; HABERMAS, 2002). I dentificamos que essa linguagem é apreendida e constrói memória no mundo da vida, o qual passa, também, a reproduzi-la em suas práticas cotidianas. Na comunicação adotada, os meios e os fins possuem um caráter reificador de processos sociais também reificados, em que a possibilidade de decisão pertence à razão dos sistemas autodirigidos, os quais determinam uma ordem social, confirmando as teorizações de Debord (1997), Canclini (1998), Habermas (2002), Adorno (2002), Jameson (2002), Morin (2007), Castells, (2008) e Ortiz (2008).

O intercâmbio entre as culturas se apresentou fortemente em nosso campo discursivo, por meio de relações de agência (tese), conflito (antítese) e síntese, que ordenaram as formações discursivas. A possibilidade de compreensão da sociedade por meio da marca global se dá, exatamente, pela leitura das sínteses geradas no embate das certezas estabelecidas desde sempre, bem como a partir dos vínculos nativos que regulam a pertença dos indivíduos com a cultura generalista racionalista. Assim, a postura ideológica global conflita-se, culturalmente, com as práticas nativas, as quais, por sua vez, adotam as mesmas estratégias, impõem suas características culturais próprias e geram uma síntese discursiva, impregnada dessa forma social. Essas práticas constituem a lógica que pode ser estendida da dialética local para compreensão da sociedade ocidental. Por outro lado, entendendo que a cultura do consumo seja uma estrutura de relacionamentos e que estes têm se revelado um importante objeto de investigação para o marketing (FULLERTON, 1988; HOWARD et al., 1991; ARNOLD; FISHER, 1996; MELLO; LEÃO, 2003), acreditamos ter contribuído com o campo de marketing no sentido de demonstrar o importante papel das marcas no interior dessa cultura. As mesmas se destacaram na condição pós-moderna de consumo por serem excelentes suportes para as experiências imateriais, caracterizadas pelo crescente fenômeno de valorização do signo. 
AAKER, D. A. Como construir marcas líderes. São Paulo: Futura, 2000

ACHUTTI, L. E. R.; HASSEN, M. N. A. Caderno de campo digital: antropologia em novas mídias. Horizontes Antropológicos, Porto Alegre, v. 10, n. 21, p. 273-289, jan./jun. 2004.

ADORNO, T. Indústria cultural e sociedade. São Paulo: Paz e Terra, 2002.

ARNOLD, M. J .; FISHER, J. E. Counterculture, cristicisms and crisis: assessing the effect of the sixties on marketing thought. Journal of Macromarketing, Spring, p.118-133, 1996.

BAUDRILLARD, J. A Sociedade de consumo. Tradução: Artur Morão. Lisboa: Edições 70, 2007.

BARBOSA, L. Sociedade de consumo. Rio de Janeiro: Jorge Zahar, 2004.

; CAMPBELL, C. O estudo do consumo nas ciências sociais

contemporâneas. In:

(Org.). Cultura consumo e identidade. Rio de Janeiro: FGV, 2007. p. 21-44.

BONI, P. C.; MORESCHI, B. M. Fotoetnografia: a importância da fotografia para o resgate etnográfico. Doc On-line, n.3, p. 137-157, dez. 2007.

BROWN, S. Postmodern marketing? European Journal of Marketing, v. 27, n.4, p. 19-34, 1993.

Como construir uma grande marca: a magia da marca Harry Potter.

Tradução: Carolina C. Coelho. São Paulo: Editora Planeta do Brasil, 2006.

CANCLI NI, N. G. Culturas híbridas: estratégias para entrar e sair da modernidade. Tradução: Heloísa P. Cintrão e Ana Regina Lessa. 2.ed. São Paulo: Edusp, 1998.

CASTELLS, M. O poder da identidade. 6a ed. São Paulo: Editora Paz e Terra, 2008.

CAVEDON, N. R. Recursos metodológicos e formas alternativas no desenvolvimento e na apresentação de pesquisas em administração. In: ENCONTRO ANUAL

DA ASSOCIAĈ̃̃ NACIONAL DE PROGRAMAS DE PÓS-GRADUAÇÃO EM

ADMI NISTRAÇÃO E PESQUISA - EnANPAD, 25., 2001, Campinas. Anais...

Campinas: ANPAD, 2001.

CHEVAlier, M.; MAZZAlovo, G. Pró Logo. São Paulo: Panda Books, 2007.

COVA, B. Community and consumption towards a definition of the "linking value" of product or services. European J ournal of Marketing, v. 31 n. 3/4, p. 297-316, 1997.

DEBORD, G. A sociedade do espetáculo. Rio de Janeiro: Contraponto, 1997.

DENZI N, N. K.; LI NCOLN, Y. S. (Org.). Handbook of qualitative research. Thousand Oaks: Sage Publications, 1994.

DOUGLAS, M.; ISHERWOOD, B. O mundo dos bens: para uma antropologia do consumo. Rio de J aneiro: Editora UFRJ , 2006.

EAGLETON, T. A idéia de cultura. Tradução: Sandra Castello Branco. São Paulo: UNESP, 2005.

EIZIRIK, M. F. Poder, saber e práticas sociais. Psico, Porto Alegre, PUCRS, v. 37, n. 1, p. 23-29, jan./abr. 2006. Disponível: <http://revistaseletronicas.pucrs.br/ojs/ index.php/revistapsico/article/view/1407/1107> Acesso em: 25 abr. 2008.

FAE, R. A genealogia em Foucault. Psicologia em Estudo, Maringá, v. 9, n. 3, p. 409-416, set./dez. 2004. Disponível: <http://www.scielo.br/pdf/pe/v9n3/v9n3a08. pdf>. Acesso em: 20 abr. 2008. 
FAIRCLOUGH, N. Discurso e mudança social. Tradução: Izabel Magalhães (Coord.). Brasília: Editora Universidade de Brasília, 2001.

FERREIRA, A. A. L. Para além dos fundamentalismos epistemológicos: o encontro de Michel Foucault e Bruno Latour na construção diferencial de um mundo comum. In: RAGO, M.; MARTINS, A.L. (Org.). Revista Aulas: Dossiê Foucault. n. 3, dez. 2006. Disponível: <http://www.unicamp.br/ aulas/> Acesso em: 18 abr. 2008.

FICHER, R. M. B. Foucault e a análise do discurso em Eeducação. Cadernos de Pesquisa, n. 114, p.197-223, nov. 2001. Disponível: <http://www6.inep.gov.br/ pesquisa/bbe-online/det. asp?cod=53108\&type=P>. Acesso em: 18 abr. 2007

FOUCAULT, M. A arqueologia do saber. 7ạ ed. Rio de Janeiro: Forense Universitária, 2007.

FULLERTON, R. A. How modern is modern marketing? Marketing's evolution and the myth of the "production era". Journal of Marketing, v.52, p.108-125, 1988.

GODOI, C. K.; BALSINI, C. P. V. A pesquisa qualitativa nos estudos organizacionais brasileiros: uma análise bibliométrica. In: BANDEIRA-DE-MELLO, R.; SILVA, A. B. (Org.). Pesquisa qualitativa em estudos organizacionais: paradigmas, estratégias e métodos. São Paulo: Saraiva, 2006. p. 89-112.

GODOY, A. S. Estudo de caso qualitativo. In: GODOI, C. K.; BANDEIRA-DEMELLO, R.; SILVA, A. B. (Org.). Pesquisa qualitativa em estudos organizacionais: paradigmas, estratégias e métodos. São Paulo: Saraiva, 2006. p. 115-146 .

HABERMAS, J. Pensamento pós-metafísico: estudos filosóficos. 2 ed. Rio de J aneiro: Tempo Brasileiro, 2002.

HARPER, D. What's new visually? In: DENZIN, N. K.; LINCOLN, Y. S (Org.). The sage handbook of qualitative research. California: Sage Publications, 2005. p. 747-762.

HOWARD, D. et al. The evolution of marketing theory in the United States and Europe. European Journal of Marketing, v.25, n.2, p.7-16, 1991

JAMESON, F. Pós-modernismo: a lógica cultural do capitalismo tardio. São Paulo: Ática, 2002.

KAPFERER, J. As marcas, capital da empresa: criar e desenvolver marcas fortes. Tradução: Arnaldo Ryngelblum. 3ạ. Ed. Porto Alegre: Bookmen, 2003.

KLEIN, N. Sem logo: a tirania das marcas em um planeta vendido. Tradução: Ryta Vinagre. 6a ed. Rio de Janeiro: Record, 2008.

KOTLER, P. Administração de marketing: a edição do novo milênio. Tradução: Bazán Tecnologia e Lingüística. São Paulo: Prentice Hall, 2000

LEÃO, A.L.M. de S.; Investigações marcárias: uma caminhada em busca de compreensão da significação das marcas pelos consumidores inspirada na segunda Ffilosofia de Ludwig Wittgenstein. Recife, 2007. 418p. Tese (Doutorado em Administração) - Programa de Pós-graduação em Administração, Centro de Ciências Sociais Aplicadas, UFPE, Recife, 2007.

; MELLO, S. C. B. de. A significação do consumo. Working paper. Recife, 2004.

Cultura e consumo: significação das marcas em contextos culturais de interação. In: ENCONTRO DE ESTUDOS MULTIDISCIPLI NARES EM CULTURA - ENECULT, 3., 2007, Salvador. Anais... Salvador: UFBa, 2007.

MCCRACKEN, G. Cultura e consumo: novas abordagens ao caráter simbólico dos bens e das atividades de consumo. Tradução: Fernanda Eugênio. Rio de Janeiro: MAUAD, 2003.

MELLO, S. C. B. Comentários: o que é o conhecimento do marketing no Brasil, afinal? RAC, v.10, n. 2, p. 203-212, abr./jun. 2006. 
; LEÃO, A.L.M.S. Prólogo ao que não é o que não pode ser que é...

marketing. Gestão.Org, Revista Eletrônica de Gestão Organizacional, v.1, n. 1, p. 76-82, jan./jun. 2003

MILLER, D. Consumption. In: TILLEY, C.Y. et al. (Org.). Handbook of material culture. London: Sage Publications Inc., 2006. p. 341-354 .

MORIN, Edgar. Cultura de massas no século XX: neurose. Tradução: Maura Ribeiro Sardinha. 9ạ Edição. Rio de Janeiro: Forense Universitária, 2007

ORTIZ, R. Mundialização e cultura. São Paulo: Brasiliense, 2007.

PEREZ, C. Signos da marca: expressividade e sensorialidade. São Paulo: Pioneira Thomson Learning, 2004

PIMENTEL F.E.; VASCONCELOS E. Foucault: da microfísica à biopolítica. In: RAGO, M.; MARTINS, A.L. (Org.). Revista Aulas: Dossiê Foucault. n.3, dez. 2006. Disponível: http://www.unicamp.br/ aulas/, Acesso em: 25 abr. 2008

ROCHA et al. Cultura e consumo: um roteiro de estudos e pesquisas. In: ENCONTRO ANUAL DA ASSOCIAÇÃO NACIONAL DE PROGRAMAS DE PÓSGRADUAÇÃO EM ADMINISTRAÇÃO E PESQUISA - EnANPAD, 23., 1999, Foz do Iguaçu. Anais... Foz do Iguaçu: ANPAD, 1999

SANT'ANNA, A. Propaganda: teoria, técnica e prática. São Paulo: Pioneira T. Learning, 2002.

SEMPRINI, A. A marca pós-moderna: poder e fragilidade da marca na sociedade contemporânea. São Paulo: Estação da Letras, 2006.

SHIMP, T. A. Propaganda e promoção: aspectos complementares da comunicação integrada de marketing. Porto Alegre: Bookman, 2002

SLATER, D. Cultura do consumo e modernidade. São Paulo: Nobel, 2002.

STAKE, R. E. Case studies. In: DENZIN, N. K; LINCOLN, Y.S (Org.). Handbook of qualitative research. Thousand Oaks: Sage Publications, 1994. p. 236-247.

THIRY-CHERQUES, H. R. Métodos estruturalistas: pesquisa em ciência e gestão. São Paulo: Atlas, 2008.

Artigo recebido em 11/ 11/ 2010.

Última versão recebida em 04/ 08/ 2011.

Artigo aprovado em 09/ 11/ 2011. 